\title{
Determinants of Health Facility Utilization at Birth in South Sudan
}

\author{
Justin Bruno Tongun ${ }^{1,2, * \mathbb{C}}$, David Mukunya ${ }^{1}\left(\mathbb{D}\right.$, Thorkild Tylleskar ${ }^{1}$, Mohamedi Boy Sebit ${ }^{3}$, \\ James K Tumwine ${ }^{4}$ and Grace Ndeezi ${ }^{4}$ \\ 1 Centre for International Health, University of Bergen, 7804 Bergen, Norway \\ 2 Department of Paediatrics, University of Juba, Juba P.O. Box 82, South Sudan \\ 3 Department of Internal Medicine, University of Juba, Juba P.O. Box 82, South Sudan \\ 4 Department of Paediatrics and Child Health, School of Medicine, College of Health Sciences, \\ Makerere University, Kampala P.O. Box 7072, Uganda \\ * Correspondence: tongunmafi@gmail.com
}

Received: 5 June 2019; Accepted: 6 July 2019; Published: 9 July 2019

\begin{abstract}
South Sudan has a high maternal mortality ratio estimated at 800 deaths per 100,000 live births. Birth in health facilities with skilled attendants can lower this mortality. In this cross-sectional study, we determined the level and determinants of health facility utilization and skilled birth attendance in Jubek State, South Sudan. Mothers of children aged less than two years were interviewed in their homes. Multivariable regression analysis was performed to determine factors associated with health facility births. Only a quarter of the mothers had given birth at health facilities, 209/810 (25.8\%; 95\% CI 18.2-35.3) and 207/810 had a skilled birth attendant (defined as either nurse, midwife, clinical officer, or doctor). Factors positively associated with health facility births were four or more antenatal visits (adjusted odds ratio (AOR) 19; 95\% CI 6.2, 61), secondary or higher education (AOR 7.9; 95\% CI 3, 21), high socio-economic status (AOR 4.5; 95\% CI 2.2, 9.4), and being primipara (AOR 2.9; 95\% CI 1.5, 5.4). These findings highlight the need for efforts to increase health facility births in South Sudan.
\end{abstract}

Keywords: childbirth; health-facility-births; skilled birth attendant; reproductive health; South-Sudan

\section{Introduction}

The global maternal mortality ratio (MMR) has dropped by $44 \%$ in the last 25 years [1]. This decline varies widely between low- and high-income countries. Low-income countries contribute $99 \%$ of the maternal deaths in the world, and sub-Saharan Africa accounts for $66 \%$ of these deaths [1].

Often, maternal deaths are due to direct obstetric causes such as postpartum haemorrhage, obstructed labour, sepsis, unsafe abortion, and hypertension [2]. These complications can be mitigated by encouraging mothers to give birth at health facilities with the help of skilled birth attendants [3]. Mothers who give birth at health facilities are also less likely to die or lose their new-borns [4-6]. Reduction of mortality in health facility births is, largely, due to skilled health workers' ability to prevent, treat, or control fatal obstetric and neonatal complications.

South Sudan has one of the highest MMR and neonatal mortality rates (NMR) in the world. The MMR was estimated to be 800 per 100,000 live births in 2015, while the NMR was about 39 per 1000 live births in the same year $[7,8]$. These figures are probably higher in rural areas and those involved in the civil war [9]. The South Sudan Demographic Household survey in 2010 report showed that only $12 \%$ of mothers used health facilities during childbirth with skilled birth attendants [10]. For South Sudan to meet the targets of the third Sustainable Development Goal (SDG) of reducing the MMR to less than 70 per 100,000 live births, and the neonatal mortality rate to less than 12/1000 
live births [11] interventions that reduce both maternal and neonatal mortality and morbidity must be implemented $[12,13]$. One such intervention is scaling up health facility births and skilled birth attendance. To design interventions that promote health facility births in South Sudan, up to date context-specific data are needed [14].

We report the level and determinants of health facility utilization and skilled birth attendance during childbirth in Jubek State, South Sudan.

\section{Subjects and Methods}

\subsection{Study Design}

This was a cross-sectional study carried out among mothers of children aged 0-23 months.

\subsubsection{Setting}

This study was carried out from October 2016-December 2016 in four counties in Jubek State, South Sudan. Jubek State has 12 Counties and one city council (Juba) with a population of about 500,000 [15]. Most of the inhabitants are ethnic Bari who speaks the Bari language. Farming is the main economic activity. The survey was carried out in four rural counties of Lodu, Luri, Mangala, and Rajaf [15].

\subsubsection{Sampling}

We used a two-stage sampling method, which is; basically, a modification of the World Health Organization (WHO) expanded programme on immunization (EPI) method for estimating vaccination coverage [16]. We listed all 43 villages and corresponding populations in the four counties and selected 30 out of 43 the villages by probability proportionate to size [16]. In each village, we selected an index house randomly and proceeded to the nearest house. The next house was selected by picking the house nearest to the index household; the one whose door was closest. From each household, we recruited one mother-infant pair. This process was repeated until a total of 27 mother-infant pairs had been interviewed from each of the 30 villages, giving us a total of 810 participants. The details of the sampling procedure have been published in the Global Health Action Journal [17].

Eight trained research assistants conversant with the study area and fluent in Bari (the local language) collected the data. The interviews were done in a private area in the mother's home, away from the other members of the family.

\subsection{Study Participants}

We included mothers of children aged 0-23 months; if a mother had two children born in the last two years, only the youngest was selected. We excluded mother-infant pairs who were not residents in the village, children with no mothers, and those whose mothers were not mentally sound to complete the interview.

\subsection{Variables}

The outcome variables included: the place of birth and skilled birth attendance. Place of birth categorized as a healthcare facility or other (home, on the way to a health facility, traditional birth attendant's house, etc.). Mothers were also asked about the person who assisted them during childbirth, and this was categorized as skilled birth attendance if they reported a healthcare worker (defined as either nurse, midwife, clinical officer, or doctor) or unskilled birth attendance. Other variables included the mothers' age categorised as $\leq 19,20-24,25-29$, and $\geq 30$ years; marital status classified as single or married; mothers' education categorized as no formal education, primary, $\geq$ secondary; antenatal care visits categorised as none, 1 to $3, \geq 4$; parity classified as 1 or $>1$ and socio-economic status categorized as quintiles Q1 (poorest), Q2 (poor), Q3 (medium), Q4 (less poor) and Q5 (least poor). The socioeconomic status was calculated using multiple correspondence analysis [18] base on: 
(a) ownership of assets such as car, phone, radio, television, fridge, cupboard, bicycle, motorcycle, house, land, (b) fuel use for cooking, and (c) assessment of household dwelling characteristics like material of the floor, roof, and house type.

\subsection{Data Analysis}

We present continuous variables as means and standard deviations; and categorical variables as proportions. We used logistic regression to assess factors associated with health facility birth and skilled birth attendance.

Factors associated with health facility births from the literature and those with a $p$-value $\leq 0.25$, and not strongly collinear with other independent variables were entered in the initial multivariate logistic regression model. We assessed for collinearity and considered factors with a variance inflation factor more than ten strongly collinear. In case of collinearity, the factor with a stronger measure of association with the dependent variable was retained, and the other dropped from the model. We used STATA version 14 (STATA Corp LLC, Texas, TX, USA) with survey set command adjusting for the multistage sampling in the data analysis.

\subsection{Ethics}

We obtained ethical approval from the Directorate of Planning, Budgeting, and Research in the Ministry of Health in South Sudan—reference number SMOH/E/JS/44.K.1. Official letters of permission were presented to the county commissioners and village chiefs. Written informed consent was obtained from the study participants after providing information about the purpose and procedures of the study. We obtained a thumbprint from participants who were unable to write. Privacy and confidentially measures were maintained throughout the study. No compensation was given to the study participants. We addressed the participants' questions regarding the survey accordingly.

\section{Results}

\subsection{Socio-Demographic and Birth Characteristics}

A total of 810 mothers were included in this survey, Table 1. The mean and standard deviation (SD) of the age of mothers was 26.6 (5.5) years. Most of the mothers were married; over half had no formal education. Only a quarter of the mothers gave birth at a health facility, 209/810 (25.8\%; $95 \%$ CI 18.2-35.3). Of the 810 mothers, 204 had had a skilled birth attendant, and five did not. Another three mothers who did not give birth at a health centre said they had a skilled birth attendant.

\subsection{Factor Associated with Health Facility Birth and Skilled Birth Attendance at Birth}

Factors linked to health facility births at bivariable level included mother's age, mother's education, one or more antenatal care visits, high socio-economic status, and maternal parity greater than one, Table 2.

Factors positively associated with health facility births in the multivariable analysis included, mother's education status, antenatal care visits, socio-economic status, and parity, Table 2.

Factors associated with skilled birth attendance in the multivariable analysis included mothers' education status, antenatal care visits, and socio-economic status, Table 3. 
Table 1. Baseline characteristics of mothers in a community survey in Jubek State, South Sudan.

\begin{tabular}{|c|c|c|}
\hline \multirow[t]{2}{*}{ Characteristics } & $\begin{array}{l}\text { All Participants } \\
\qquad N=810\end{array}$ & $\begin{array}{l}\text { Health Facility Births } \\
\qquad N=209(25.8 \%)\end{array}$ \\
\hline & $n(\%)$ & $n(\%)$ \\
\hline \multicolumn{3}{|l|}{ Age of the mother } \\
\hline$\leq 19$ & $89(11.0)$ & $35(16.8)$ \\
\hline $20-24$ & $195(24.1)$ & $67(32.1)$ \\
\hline $25-29$ & $279(34.4)$ & $59(28.2)$ \\
\hline $30-34$ & $173(21.4)$ & $40(19.1)$ \\
\hline$\geq 35$ & $74(9.1)$ & $8(3.8)$ \\
\hline \multicolumn{3}{|l|}{ Marital status } \\
\hline Single & $17(2.1)$ & $6(2.9)$ \\
\hline Married & $793(97.9)$ & $203(97.1)$ \\
\hline \multicolumn{3}{|l|}{ Mother's education } \\
\hline None & $516(63.7)$ & $63(30.1)$ \\
\hline Primary & $228(28.2)$ & $96(45.9)$ \\
\hline$\geq$ Secondary & $66(8.2)$ & $50(23.9)$ \\
\hline \multicolumn{3}{|c|}{ Mother's employment } \\
\hline Unemployed & $690(85.2)$ & $166(79.4)$ \\
\hline Employed & $120(14.8)$ & $43(20.6)$ \\
\hline \multicolumn{3}{|l|}{ Antenatal care visits } \\
\hline None & $165(20.4)$ & $4(1.9)$ \\
\hline $1-3$ & $444(54.8)$ & $98(46.9)$ \\
\hline$\geq 4$ & $201(24.8)$ & 107 (51.2) \\
\hline \multicolumn{3}{|l|}{ Parity } \\
\hline 1 & $138(17.0)$ & $61(29.2)$ \\
\hline$>1$ & $672(83.0)$ & $148(70.8)$ \\
\hline \multicolumn{3}{|c|}{ Socio-economic quintiles } \\
\hline Poorest (Q1) & $286(35.3)$ & $28(13.4)$ \\
\hline Poor (Q2) & $95(11.7)$ & $20(9.6)$ \\
\hline Medium (Q3) & $114(14.1)$ & $17(8.1)$ \\
\hline Less poor (Q4) & 154 (19.0) & $51(24.4)$ \\
\hline Least Poor (Q5) & $161(19.9)$ & $93(44.4)$ \\
\hline
\end{tabular}

Table 2. Bivariate and multivariate logistic regression analysis of health facility birth in a community survey in Jubek State, South Sudan

\begin{tabular}{|c|c|c|}
\hline \multirow[t]{2}{*}{ Characteristic } & $\begin{array}{l}\text { Bi-Variable } \\
\quad N=810\end{array}$ & $\begin{array}{l}\text { Multivariable Model } 1 \\
\qquad N=810\end{array}$ \\
\hline & OR $(95 \% C I)$ & AOR $(95 \% C I)$ \\
\hline \multicolumn{3}{|l|}{ Mother's age } \\
\hline$\leq 19$ & 1 & 1 \\
\hline $20-24$ & $0.8(0.46,1.4)$ & $0.9(0.44,1.9)$ \\
\hline $25-29$ & $0.4(0.24,0.7)$ & $0.8(0.31,2.02)$ \\
\hline $30-34$ & $0.5(0.2,1.1)$ & $0.9(0.32,2.7)$ \\
\hline$\geq 35$ & $0.2(0.06,0.6)$ & $0.5(0.14,1.9)$ \\
\hline \multicolumn{3}{|l|}{ Marital status } \\
\hline Married & 1 & \\
\hline Single & $1.6(0.46,5.4)$ & - \\
\hline \multicolumn{3}{|l|}{ Mother's education } \\
\hline No formal education & 1 & 1 \\
\hline Primary & $5.2(3.2,8.5)$ & $3.1(1.9,5.2)$ \\
\hline$\geq$ Secondary & $22(11,46)$ & $7.9(3,21)$ \\
\hline
\end{tabular}


Table 2. Cont.

\begin{tabular}{ccc}
\hline Characteristic & $\begin{array}{c}\text { Bi-Variable } \\
\mathbf{N}=\mathbf{8 1 0}\end{array}$ & $\begin{array}{c}\text { Multivariable Model 1 } \\
\mathbf{N}=\mathbf{8 1 0}\end{array}$ \\
\cline { 2 - 3 } & OR $\mathbf{( 9 5 \% \mathbf { C I } )}$ & AOR (95\%CI) \\
\hline Mother's employment & & 1 \\
Unemployed & 1 & $1.2(0.6,2.4)$ \\
Employed & $1.8(0.94,3.3)$ & \\
Antenatal care visits & & 1 \\
None & 1 & $5.2(1.7,16)$ \\
$1-3$ & $11(4.2,31)$ & $19(6.2,61)$ \\
$\geq 4$ & $46(15,140)$ & \\
Parity & & $2.9(1.5,5.4)$ \\
1 & $2.9(1.8,4.5)$ & 1 \\
$>1$ & 1 & 1 \\
Poorest (Q1) & & $1.7(0.8,3.6)$ \\
Poor (Q2) & 1 & $1.3(0.5,3.0)$ \\
Medium (Q3) & $2.5(1.2,4.9)$ & $2.4(1.1,5.0)$ \\
Less poor (Q4) & $1.6(0.64,4.1)$ & $4.5(2.2,9.4)$ \\
Least poor (Q5) & $4.6(2.3,9.3)$ &
\end{tabular}

Table 3. Bi-variable and multivariable logistic regression analysis of skilled birth attendance in a community survey in Jubek State, South Sudan

\begin{tabular}{|c|c|c|}
\hline \multirow[t]{2}{*}{ Characteristic } & $\begin{array}{l}\text { Bi-Variable } \\
\quad N=810\end{array}$ & $\begin{array}{c}\text { Multivariable Model } 2 \\
\qquad N=810\end{array}$ \\
\hline & OR $(95 \% \mathrm{CI})$ & AOR $(95 \% C I)$ \\
\hline \multicolumn{3}{|l|}{ Mother's age } \\
\hline$\leq 19$ & 1 & 1 \\
\hline $20-24$ & $0.93(0.54,1.60)$ & $1.18(0.55,2.52)$ \\
\hline $25-29$ & $0.44(0.25,0.75)$ & $0.88(0.37,2.12)$ \\
\hline $30-34$ & $0.51(0.22,1.18)$ & $1.10(0.40,3.08)$ \\
\hline$\geq 35$ & $0.21(0.07,0.61)$ & $0.61(0.17,2.14)$ \\
\hline \multicolumn{3}{|l|}{ Marital status } \\
\hline Single & 1 & \\
\hline Married & $0.48(0.18,1.3)$ & - \\
\hline \multicolumn{3}{|l|}{ Mother education } \\
\hline No formal education & 1 & 1 \\
\hline Primary & $5.2(3.1,8.7)$ & $3.1(1.79,5.37)$ \\
\hline$\geq$ Secondary & $22.9(11.4,45.9)$ & $8.2(3.18,21.27)$ \\
\hline \multicolumn{3}{|l|}{ Mother employment } \\
\hline Unemployed & 1 & 1 \\
\hline Employed & $1.6(0.89,3.1)$ & $1.05(0.53,2.08)$ \\
\hline \multicolumn{3}{|l|}{ Antenatal care visits } \\
\hline None & 1 & 1 \\
\hline $1-3$ & $8.7(3.5,21.9)$ & $3.93(1.52,10.15)$ \\
\hline$\geq 4$ & $36.4(11.9,111.7)$ & $15.17(5.53,41.58)$ \\
\hline \multicolumn{3}{|l|}{ Parity } \\
\hline$>1$ & 1 & 1 \\
\hline 1 & $2.7(1.8,4.3)$ & $2.9(1.65,5.16)$ \\
\hline \multicolumn{3}{|l|}{ Wealth Quintiles } \\
\hline Poorest (Q1) & 1 & 1 \\
\hline Poor (Q2) & $2.5(1.3,4.8)$ & $0.61(0.80,3.54)$ \\
\hline Medium (Q3) & $1.6(0.67,3.9)$ & $1.26(0.55,2.85)$ \\
\hline Less poor (Q4) & $4.3(2.2,8.3)$ & $2.20(1.123,4.30)$ \\
\hline Wealthiest (Q5) & $12.6(6.8,23.2)$ & $4.64(2.38,9.03)$ \\
\hline
\end{tabular}




\section{Discussion}

This survey found low levels of utilization of health facilities and skilled birth attendance during childbirth; only a quarter of mothers utilized health facilities or received skilled birth attendance during childbirth.

The proportion of mothers who gave birth in a health facility was higher than that observed in the nation-wide South Sudan Household Survey (SSHS) conducted in 2010, which showed that only $12 \%$ of mothers gave birth in a health facility [10]. These proportions cannot be compared as the geographical coverage was different. In fact, the study area surveyed is close to Juba. In the rest of the country, health facility utilization is likely to be lower than what we observed. Therefore, the proportion of mothers who give birth at health facilities is still alarmingly deficient. This could be partly due to the insecurity [19] resulting from the on-going civil unrest in South Sudan, which has hindered improvement in the necessary infrastructure. Instability also discourages mothers from utilizing services, especially during the night [19-21]. Furthermore, socioeconomic consequences and shocks of war lead to poor health service delivery and utilization $[9,22,23]$. Also, the low use of health facilities for childbirth could be due to supply-side reasons such as poor quality of health care [24]. Low-quality health care is known to discourage women from using health facilities [21]. There could also be socio-cultural factors such as fear of dignity violation [25] that discourage mothers from seeking health care during childbirth.

The factors associated with giving birth at a health facility or receiving skilled birth attendance during childbirth included: having attended more antenatal care (ANC) visits, mother's education status, higher socio-economic status, and being a first-time mother. These factors were comparable to the results of a recent study on the risk factors for not using health facility at birth in South Sudan [26].

Antenatal care visit was associated with health facility births. Mothers who had attended at least four ANC visits were 19 times more likely to deliver in health facilities, compared to others who did not attend any antenatal care. This was similar to findings from Tanzania [27]. Women who attended ANC several times could have gained knowledge and understanding of the advantages of a facility birth. Further, women could also have become familiar with the health workers during the ANC visits and were inspired to give birth in health facilities [28].

We also found that the higher the mothers' education, the more likely she was to give birth in a health facility. These mothers were more likely to engage in health seeking behaviours due to higher knowledge levels, and indirectly through education's influence on other factors such as income [29,30].

In our study, mothers of higher socioeconomic status were more likely to give birth at a health facility or receive skilled assistance when giving birth. Women of lower economic status might have had difficulties in finding transport or meeting indirect costs related to childbirth, and hence barred from seeking institutional delivery [19].

A recent qualitative study by Wilunda and colleagues found political instability/ inter-communal conflict, lack of health facility infrastructure, shortage of medical supplies, socio-cultural practices, perception of childbirth, quality of obstetric care as potential factors influencing health facility-based birth in South Sudan [19]. In sub-Sahara Africa, a body of evidence found several factors that directly influenced health facility utilization during childbirth [31-33]. These factors include poor transport infrastructure, lack of finance for transport, indirect cost of obstetric care, distant to health facility, shortage of skilled health workers, suboptimal training of health workers, poor quality of obstetric care characterised by long waiting time, weak referral system and poor staff interpersonal skills, and attitude.

The findings in this study highlight the need to promote health facility births, antenatal care, the general economic situation of the population, and girl child education. The government in South Sudan could emulate evidence-based integrated multi-level practices that have worked in other settings such as: introduction of policies and programmes that support health facility-based birth, training of health workers, building more health facilities, improving referral systems, and addressing issues related to affordability and financial risk associated with access to obstetric services [13,31]. Furthermore, 
the stakeholders should pay close attention to traditional, socio-cultural and socio-economic factors that are critical in delayed decision making in seeking obstetric services, and address women's concerns regarding supportive attendance during birth [34].

One strength of this study is that we conducted a community-based survey, in a period of insecurity, where most studies on the subject are either hospital-based or qualitative. To the best of our knowledge, this study provides the first community-based estimate of health facility births in South Sudan since 2010. These data can be used to generate better estimates of health facility births and skilled childbirth in rural South Sudan. However, we did not ask for a history of pregnancy, measure some factors such as distance to the health facility, and complications during previous childbirth, which are essential determinants of place of birth. Lastly, this study was conducted in one state and is unlikely to be generalizable to the whole country.

\section{Conclusions}

We found that only a quarter of the women gave birth in a health facility in an area close to the capital Juba in South Sudan. Other areas of the country are likely to have even lower attendance. Factors positively associated with health facility births were antenatal care visits, secondary or higher maternal education, high socio-economic status, and primiparity. These findings highlight the need for efforts to increase health facility births and skilled attendance in South Sudan. There is also an urgent need to conduct a broader community-based mixed methods study to provide an in-depth understanding of barriers and facilitators of health facility utilization during childbirth in South Sudan.

Author Contributions: J.B.T., D.M., J.K.T., T.T., G.N. conceived, designed, and supervised the study, analysed the data, and wrote the first draft of the manuscript. J.K.T., D.M., T.T., G.N., M.B.S. participated in the interpretation of results and critically reviewed the manuscript. All authors have read and approved the final version of the manuscript.

Funding: This study was funded by Norad and the Norwegian program for capacity building in higher education and research for development (NORHED) through the Survival PLUSS project (No UGA-13-0030) at Makerere University and University of Bergen.

Acknowledgments: We are indebted to Norad for their Norwegian program for capacity building in higher education and research for development (NORHED) and the Survival PLUSS project (No UGA-13-0030) for funding this study. We acknowledge the research assistants and study participants for their contribution.

Conflicts of Interest: The authors declare no conflicts of interests.

\section{References}

1. Trends in Maternal Mortality. 1990 to 2015: Estimates by WHO, UNICEF, UNFPA, World Bank Group and the United Nations Population Division. ISBN 978924 1565141. Available online: https://openknowledge. worldbank.org/bitstream/handle/10986/23550/report.pdf;sequence=1 (accessed on 5 July 2019).

2. Ronsmans, C.; Graham, W.J. Maternal mortality: Who, when, where, and why. Lancet 2006, 368, 1189-1200. [CrossRef]

3. Kohi, T.W.; Mselle, L.T.; Dol, J.; Aston, M. When, where and who? Accessing health facility delivery care from the perspective of women and men in Tanzania: A qualitative study. BMC Health Serv. Res. 2018, 18, 564. [CrossRef]

4. Kinney, M.V.; Kerber, K.J.; Black, R.E.; Cohen, B.; Nkrumah, F.; Coovadia, H.; Nampala, P.M.; Lawn, J.E.; Axelson, H.; Bergh, A.M.; et al. Sub-Saharan Africa's mothers, newborns, and children: Where and why do they die? PLoS Med. 2010, 7, e1000294. [CrossRef] [PubMed]

5. Kibria, G.M.A.; Burrowes, V.; Choudhury, A.; Sharmeen, A.; Ghosh, S.; Mahmud, A.; Kc, A. Determinants of early neonatal mortality in Afghanistan: An analysis of the Demographic and Health Survey 2015. Glob. Health 2018, 14, 47. [CrossRef] [PubMed]

6. Lawn, J.E.; Blencowe, H.; Oza, S.; You, D.; Lee, A.C.; Waiswa, P.; Lalli, M.; Bhutta, Z.; Barros, A.J.; Christian, P.; et al. Every Newborn: Progress, priorities, and potential beyond survival. Lancet 2014, 384, $189-205$. [CrossRef] 
7. Sami, S.; Kerber, K.; Kenyi, S.; Amsalu, R.; Tomczyk, B.; Jackson, D.; Dimiti, A.; Scudder, E.; Meyers, J.; Umurungi, J.P.C.; et al. State of newborn care in South Sudan's displacement camps: A descriptive study of facility-based deliveries. Reprod. Health 2017, 14, 161. [CrossRef] [PubMed]

8. Alkema, L.; Chou, D.; Hogan, D.; Zhang, S.; Moller, A.B.; Gemmill, A.; Fat, D.M.; Boerma, T.; Temmerman, M.; Mathers, C.; et al. Global, regional, and national levels and trends in maternal mortality between 1990 and 2015, with scenario-based projections to 2030: A systematic analysis by the UN Maternal Mortality Estimation Inter-Agency Group. Lancet 2016, 387, 462-474. [CrossRef]

9. Salama, P.; Spiegel, P.; Talley, L.; Waldman, R. Lessons learned from complex emergencies over past decade. Lancet 2004, 364, 1801-1813. [CrossRef]

10. The Republic of South Sudan: The Sudan Household Health Survey 2010. Available online: https://www.google.com/url?sa=t\&rct=j\&q=\&esrc=s\&source=web\&cd=3\&cad=rja\&uact=8\&ved= 2ahUKEwjv1bvp4q7iAhXnsaQKHd5-DQYQFjACegQIAhAB\&url=https\%3A\%2F\%2Freliefweb.int\% 2Freport\%2Fsouth-sudan-republic\%2Frepublic-south-sudan-sudan-household-health-survey-2010\& usg=AOvVaw0RS2TYlvkSGkfxFXCOvxft (accessed on 5 July 2019).

11. Sustainable Development Goals. Available online: http://www.un.org/sustainabledevelopment/summit/ (accessed on 5 July 2019).

12. De Bernis, L.; Kinney, M.V.; Stones, W.; Ten Hoope-Bender, P.; Vivio, D.; Leisher, S.H.; Bhutta, Z.A.; Gulmezoglu, M.; Mathai, M.; Belizan, J.M.; et al. Stillbirths: Ending preventable deaths by 2030. Lancet 2016, 387, 703-716. [CrossRef]

13. Campbell, O.M.; Calvert, C.; Testa, A.; Strehlow, M.; Benova, L.; Keyes, E.; Donnay, F.; Macleod, D.; Gabrysch, S.; Rong, L.; et al. The scale, scope, coverage, and capability of childbirth care. Lancet 2016, 388, 2193-2208. [CrossRef]

14. Koblinsky, M.; Moyer, C.A.; Calvert, C.; Campbell, J.; Campbell, O.M.; Feigl, A.B.; Graham, W.J.; Hatt, L.; Hodgins, S.; Matthews, Z.; et al. Quality maternity care for every woman, everywhere: A call to action. Lancet 2016, 388, 5-11. [CrossRef]

15. Jubek State. Available online: https://en.wikipedia.org/wiki/Jubek_State (accessed on 5 July 2019).

16. A Simplified General Method for Cluster-Sample Surveys of Health in Developing Countries. Available online: http://www.who.int/iris/handle/10665/47585 (accessed on 5 July 2019).

17. Tongun, J.B.; Sebit, M.B.; Ndeezi, G.; Mukunya, D.; Tylleskar, T.; Tumwine, J.K. Prevalence and determinants of pre-lacteal feeding in South Sudan: A community-based survey. Glob. Health Action 2018, 11, 1523304. [CrossRef] [PubMed]

18. Howe, L.D.; Hargreaves, J.R.; Huttly, S.R. Issues in the construction of wealth indices for the measurement of socio-economic position in low-income countries. Emerg. Themes Epidemiol. 2008, 5. [CrossRef] [PubMed]

19. Wilunda, C.; Scanagatta, C.; Putoto, G.; Takahashi, R.; Montalbetti, F.; Segafredo, G.; Betran, A.P. Barriers to institutional childbirth in Rumbek North County, South Sudan: A qualitative study. PLoS ONE 2016, 11, e0168083. [CrossRef] [PubMed]

20. Mugo, N.S.; Dibley, M.J.; Damundu, E.Y.; Alam, A. Barriers faced by the health workers to deliver maternal care services and their perceptions of the factors preventing their clients from receiving the services: A qualitative study in South Sudan. Matern. Child Health J. 2018, 22, 1598-1606. [CrossRef] [PubMed]

21. Mugo, N.S.; Dibley, M.J.; Damundu, E.Y.; Alam, A. “The system here isn't on patients' side" —Perspectives of women and men on the barriers to accessing and utilizing maternal healthcare services in South Sudan. BMC Health Serv. Res. 2018, 18, 10. [CrossRef]

22. Casey, S.E.; Chynoweth, S.K.; Cornier, N.; Gallagher, M.C.; Wheeler, E.E. Progress and gaps in reproductive health services in three humanitarian settings: Mixed-methods case studies. Conflict Health 2015, 9, S3. [CrossRef] [PubMed]

23. Kruk, M.E.; Kujawski, S.; Moyer, C.A.; Adanu, R.M.; Afsana, K.; Cohen, J.; Glassman, A.; Labrique, A.; Reddy, K.S.; Yamey, G. Next generation maternal health: External shocks and health-system innovations. Lancet 2016, 388, 2296-2306. [CrossRef]

24. Berendes, S.; Lako, R.L.; Whitson, D.; Gould, S.; Valadez, J.J. Assessing the quality of care in a new nation: South Sudan's first national health facility assessment. Trop. Med. Int. Health 2014, 19, 1237-1248. [CrossRef]

25. Kane, S.; Rial, M.; Kok, M.; Matere, A.; Dieleman, M.; Broerse, J.E.W. Too afraid to go: Fears of dignity violations as reasons for non-use of maternal health services in South Sudan. Reprod. Health 2018, 15, 51. [CrossRef] 
26. Mugo, N.S.; Agho, K.E.; Dibley, M.J. Risk factors for non-use of skilled birth attendants: Analysis of South Sudan household survey, 2010. Matern. Child Health J. 2016, 20, 1266-1279. [CrossRef] [PubMed]

27. Bishanga, D.R.; Drake, M.; Kim, Y.M.; Mwanamsangu, A.H.; Makuwani, A.M.; Zoungrana, J.; Lemwayi, R.; Rijken, M.J.; Stekelenburg, J. Factors associated with institutional delivery: Findings from a cross-sectional study in Mara and Kagera regions in Tanzania. PLoS ONE 2018, 13, e0209672. [CrossRef] [PubMed]

28. Jennings, L.; Yebadokpo, A.S.; Affo, J.; Agbogbe, M. Antenatal counseling in maternal and newborn care: Use of job aids to improve health worker performance and maternal understanding in Benin. BMC Pregnancy Childbirth 2010, 10. [CrossRef] [PubMed]

29. Margolis, R. Educational differences in healthy behavior changes and adherence among middle-aged Americans. J. Health Soc. Behav. 2013, 54, 353-368. [CrossRef] [PubMed]

30. Cutler, D.M.; Lleras-Muney, A. Understanding differences in health behaviors by education. J. Health Econ. 2010, 29, 1-28. [CrossRef] [PubMed]

31. Geleto, A.; Chojenta, C.; Musa, A.; Loxton, D. Barriers to access and utilization of emergency obstetric care at health facilities in sub-Saharan Africa: A systematic review of literature. Syst. Rev. 2018, 7, 183. [CrossRef]

32. Kyei-Nimakoh, M.; Carolan-Olah, M.; McCann, T.V. Barriers to obstetric care at health facilities in sub-Saharan Africa-A systematic review protocol. Syst. Rev. 2015, 4. [CrossRef] [PubMed]

33. Kyei-Nimakoh, M.; Carolan-Olah, M.; McCann, T.V. Access barriers to obstetric care at health facilities in sub-Saharan Africa-A systematic review. Syst. Rev. 2017, 6, 110. [CrossRef]

34. Bohren, M.A.; Hunter, E.C.; Munthe-Kaas, H.M.; Souza, J.P.; Vogel, J.P.; Gulmezoglu, A.M. Facilitators and barriers to facility-based delivery in low- and middle-income countries: A qualitative evidence synthesis. Reprod. Health 2014, 11, 71. [CrossRef]

(C) 2019 by the authors. Licensee MDPI, Basel, Switzerland. This article is an open access article distributed under the terms and conditions of the Creative Commons Attribution (CC BY) license (http://creativecommons.org/licenses/by/4.0/). 